\title{
A Review on Gun Barrel Erosion
}

\author{
Abhilash A. Putti ${ }^{*}$, M. R. Chopade ${ }^{\dagger}$ and P. E. Chaudhari ${ }^{\dagger}$ \\ †Department of Mechanical Engineering, MIT College of Engineering, Pune India \\ Accepted 03 March 2016, Available online 15 March 2016, Special Issue-4 (March 2016)
}

\begin{abstract}
The Erosion of Gun Barrels leads to reduced gun performance and availability, and increases the expense of barrel replacement over the life time of a gun system. Wear in gun barrel usually increases the bore diameter near the commencement of rifiling. The wear spreads forwards toward the muzzle as the gun is fired continuously. The point of maximum wear remains near the commencement of rifiling. Worn barrels are objectionable because they allow gas to escape past the shot thus reducing muzzle velocity, range and accuracy. As the muzzle begins to wear the shot loses directional stability.The total wear that can be tolerated is called condemning limit. Its value depends on the size of the gun, the required accuracy and the factor of safety that must be maintained against catastrophic fatigue failure. On average barrels are condemned when the bore diameter increases by about 5\%. Wear depends not only on the thermal load but also on the surface metallurgy of the bore and the chemical interactions between the propellant gas and the bore surface. The erosivity of different propellants have been investigated over the years using various numerical methods and some works have tested propellants or propellant gases in some form of simulated gun. This paper discusses the various types of erosion taking place in the gun barrel. It also gives a list on various methods developed over the years to mitigate the gun barrel wear.
\end{abstract}

Keywords:Barrel erosion, condemning limit, erosivity of propellant.

\section{Introduction}

Wear and erosion was probably first identified as a significant problem for guns in 1886 when Abel stated "The great increase which has been taking place during the last 25 years in the power of artillery has brought the subject of erosion of gun barrels into prominence, and it is not too much to say that it now forms one of the chief difficulties to be encountered by the makers of a heavy gun. As far as can be seen at present, its sufficient mitigation is the one great difficulty, which seems likely to impose a limit on the sizeand power of ordnance in future". The major contributors to wear and erosion of gun barrels are: thermal factors, chemical factors and mechanical factors. The relative contributions of these factors vary from system to system. Thermal and chemical effects are considered to be the dominant factors. When a gun is fired the barrel wall is subjected to heating by a hot gas, typically $3000 \mathrm{~K}$ and at $400 \mathrm{MPa}$, for up to $20 \mathrm{~ms}$. This barrel heating leads to softening, thermal phase transformation and melting of the bore surface. Considerable thermal heating, due to forced convection, can be caused by gas wash between the projectile driving band and the bore surface.

The main constituents of propellant gases are $\mathrm{CO}$, $\mathrm{CO}_{2}, \mathrm{H}_{2}, \mathrm{H}_{2} \mathrm{O}$ and $\mathrm{N}_{2}$. Minor components will include

*Corresponding author: Abhilash A. Putti
$\mathrm{NH}_{3}, \mathrm{CH}_{4}$, NO, free radicals and ions. Gun propellants are formulated to be oxygen deficient so their combustion products are reducing in nature. These gases react at the bore surface. Carbon and nitrogen diffuse into the barrel, softening the bore surface.

Mechanical contributions to wear arise from the propellant gases and the projectile. Unburned propellant and small solid particles from the primer, and other sources, are entrained in the high velocity gas flow and have an abrasive effect on the bore surface. For a rifled barrel, mechanical wear arises from the engraving of the driving band into the lands and grooves at the commencement of rifling. This process causes considerable stress on the gun barrel. The spinning of the projectile, as it travels along the barrel, causes further mechanical wear. For rifled and smooth bore barrels the radial pressure between the drivingband and the bore produces friction and an abrasive action on the bore surface.

Most wear occurs around the commencement of rifling. However, significant wear can occur at the muzzle end due mainly to the projectile motion but also due to particulate abrasion. Ways to mitigate wear and erosion in gun barrels include liners, chromium plating, ablators, and wear-reducing additives to the propellant and low flame temperature propellants.

\section{Theory of Gun Wear}

When a gun if fired the maximum bore temperature rises to about $1000^{\circ} \mathrm{C}$ in about the same time it takes to 
reach the maximum pressure. The temperature rise is highest near to the commencement of rifling and corresponds to the point of maximum wear. The temperature rise $0.5 \mathrm{~mm}$ below the surface is typically $50^{\circ} \mathrm{C}$. This step temperature gradient causes high compressive thermal stresses. At the same time the hardness of the surface is greatly reduced. The depth of metal removed may vary between $0.1 \mu \mathrm{m}$ and $100 \mu \mathrm{m}$ per round depending on the kinetic energy of the impinging gas, the thermal stress level and the hardness of the surface. Gas leakage is thought o be more likely mechanism. The erosion zone is imagined to travel down the barrel behind the shot. This form of wear is complicated by the presence of various chemical species in the propellant. It is now well established that species in the propellant gas. Is now well established that species from the propellant gas diffuse into the surface changing its resistance to wear. Krishnan et al has found that atomic hydrogen removes carbon from the surface and this softens it whereas atomic nitrogen 'nitrides' the surface and hardens it. These diffusions occur vary rapidly and it must be assumed that they occur not as a conventional diffusion but as thermal diffusion in which the very high heat flow causes a coupled irreversible flow of atomic species. This model of gun wear includes the three important features of heat transfer, surface hardness and propellant composition. The diametrical wear per round can be written as (Lawton, B):

$\mathrm{w}=\mathrm{A} \exp (1.5 \mathrm{Tmax} / \mathrm{Bo})$

Where,

The constant A is called propellant wear coefficient.Its value depends on the composition of the propellant and also on the hot hardness of the bore surface.

The constant B depends only on the hot hardness characteristics of the bore surface which can be written as (Lawton, B):

$\mathrm{H}=\mathrm{H}_{\mathrm{o}} \exp \left(-\mathrm{T} / \mathrm{B}_{\mathrm{o}}\right)$

If the steel barrel is plated then the values of ' $A$ ' and ' $\mathrm{B}$ ' can be expected to change but if the propellant is changed only the values of ' $A$ ' changes.

The thermal load on the gun is represented by the maximum bore temperature; its value may be calculated from the semi empirical equation proposed by Thornhill (Lawton, $B$ ):

$\frac{T_{f}-T_{i}}{T_{\max }-T_{i}}=1.7+670 \frac{d^{2.22}}{m^{0.86}}$

Where,

$\mathrm{T}_{\mathrm{f}}$ - Flame temperature,

$\mathrm{T}_{\max }$ - Maximum Bore temperature

$\mathrm{T}_{\mathrm{i}}$-Initial temperature

This equation assumes the thermal properties of Gun Steel and is in kilograms. On measuring the temperature using a fast response thermocouple (response time-1 $1 \mu \mathrm{s}$ ) and comparing it with the results obtained from the equation (3), there is little difference. Thus equation (3) gives a temperature that is proportional to the real bore temperature. Measurements of total heat transfer on guns suggest that equation (3) needs to be modified to allow for muzzle velocity. Therefore the maximum temperature can be calculated using (Lawton, B):

$\frac{T_{f}-T_{i}}{T_{\max }-T_{i}}=1.7+670 \frac{d^{2.22}}{m^{0.86}} \sqrt{\frac{900}{C_{m}}}$

Where,

$\mathrm{C}_{\mathrm{m}}$ - Muzzle velocity ( $\mathrm{m} / \mathrm{s}$ ).

$\mathrm{m}$ - Mass of the propellant charge, $\mathrm{kg}$.

$\mathrm{d}$ - Diameter of the bore.

\subsection{Thermal Influences on wear}

A large number of service wear measurements were collected by Thornhill to which even the measurements made by Cuthbert and Farry and Austin et al may be added and a Scatter diagram between wear per round v/s Maximum temperature is plotted. (See Ref 2 for the scatter plot diagram) The data covers some 60 observations made on about 30 different guns. The observations from the Scatter plot were:

1. Wear is very sensitive to small changes in bore temperature. An increase in maximum temperature by $10 \%$ from $900^{\circ} \mathrm{C}$ to $990^{\circ} \mathrm{C}$ increases the wear rate by $276 \%$. Also it was well noted that large wear rates occur at temperature well below the melting point of the gun steel. This shows that in service Guns the mechanism of erosion cannot normally be 'melt and wipe' type.

2. Also the guns were fired using a variety of propellants each of which is expected to have a unique wear coefficient. This enabled the comparison between wear produced between the cool propellants and that produced by hot propellants. It was observed that hot propellants are less erosive than cool propellants.

\subsection{Chemical Influences on wear}

Izod and Baker's measurements show a direct link between wear and chemical composition. Atomic hydrogen diffused into the steel surface, reacted with the carbon and thus decarbonized the surface. Atomic nitrogen, on the other hand, appeared to 'nitride' the surface. Therefore a look at the relation between wear coefficient and composition seems necessary. The propellant gas is composed of five major components, $\mathrm{CO}, \mathrm{CO}_{2}, \mathrm{H} 2, \mathrm{H}_{2} \mathrm{O}$ and $\mathrm{N}_{2}$ and six more reduced species such as $\mathrm{OH}, \mathrm{H}, \mathrm{O}_{2}, \mathrm{O}, \mathrm{N}$, $\mathrm{NO}$ etc. Hot propellants contain less $\mathrm{H}_{2}$ and more $\mathrm{N}_{2}$.

A multiple regression analysis has been used to calculate the relation between the propellant wear coefficient and the composition. The dissociated 
species are considered as a single variable (\%R), in order to reduce the number of variables. The equation is written as follows:

$\mathrm{A}=\exp \left(\mathrm{a} 1 \% \mathrm{CO}_{2}+\mathrm{a}_{2} \% \mathrm{CO}+\mathrm{a}_{3} \% \mathrm{H}_{2} \mathrm{O}+\mathrm{a}_{4} \% \mathrm{H}_{2}+\mathrm{a}_{5}\right.$ $\left.\% \mathrm{~N}_{2}+\mathrm{a}_{6} \% \mathrm{R}+\mathrm{a}_{7}\right)$

Thirteen samples are used to determine seven coefficients. The exponential form is simply chosen to avoid the possibility of negative values of wear coefficient. Multiple regression yields:

$\mathrm{A}=\exp (0.23 \% \mathrm{CO} 2+0.27 \% \mathrm{CO}+0.28 \% \mathrm{H} 2 \mathrm{O}+0.74$

$\% \mathrm{H} 2+0.16 \% \mathrm{~N} 2+1.55 \% \mathrm{R}-31.36)$

Which has a goodness fit for $r^{2}=0.886$.

The Equation (6) gives sufficient good results for good fit. The wear coefficient has been seen to be very sensitive to the dissociated products $\% \mathrm{R}$.

\section{Erosion Mechanisms}

Gun barrel erosion mechanisms are categorized as chemical, thermal and mechanical. These categories act together in concert to erode gun barrels. The various chemical processes included are carburizing or oxidizing reactions at the bore surface, which results in ablation and deterioration of material properties. Diffusion of propellantgas species into the gun steel and subsurface reactions also occur. Thermal erosion mechanism is associated with phase changes, melting, and cracking of the bore surface due to the expansion and contraction related with thermal cycling. Finally the direct impingement of gas and solid particulate on the bore surface causes Mechanical erosion. There are other contributors to mechanical erosion like shearing action of the flow, removal of material by driving bands, and crack propagation due to ballistic pressure cycles. Etc. Fig1. gives the schematic diagram of the various erosion mechanisms taking part in the erosion process.

\subsection{Chemical Erosion}

Solid propellant combustion produces carbon monoxide, carbon dioxide, hydrogen, water vapour and nitrogen, in varying proportions depending on the particular formulation of the propellant. Knowing the erosive action of these gaseous species, one can reduce the erosion action of these gaseous species by modifying the solid propellant composition. Correlations relating species erosivity have been developed by some researchers through analysis of large sets of results obtained from experimental firings. The same problem has been approached by certain researchers by understanding the chemical reaction pathways which influence the erosion process.

Lawton produced two semi-empirical correlations relating gas species to erosion levels, which are equations (1) and (5) mentioned above.
Though Lawton's correlations are useful, they do not explain why erosivity is dependent on thecomposition of the propellant gas. Kimura then postulated on analyzing the correlation that variations in species concentration influence erosion primarily through corresponding changes in heat transfer from the gas to the bore surface. He then separated the thermal and chemical effects of gas composition. The relative contribution of chemical erosivity to the total erosivity for each species is order was estimated by Kimura as follows:

$\mathrm{CO}_{2}>\mathrm{CO}>\mathrm{H}_{2} \mathrm{O}>\mathrm{H}_{2}>0>\mathrm{N}_{2}$

Nitrogen which is diatomic has been found to have protective influence chemically. Kimura then used these results to develop low erosivity, high nitrogen content, low vulnerability propellant.

The erosion by propellant species is caused by two different processes. First, weaker, lower melting point compounds, which are easily removed by thermal and mechanical processes, are caused by surface reactions between the hot gas species and the bore material produce. Second, rapid thermally-driven diffusion of gas species in the radial direction, from the bore surface into the barrel material, results in interstitial atoms in the lattice of the bore metal, there by altering the structure, physical properties and melting point of the gun steel. This result in material which has decreased strength, increased brittleness, thus becomes more susceptible to erosion.

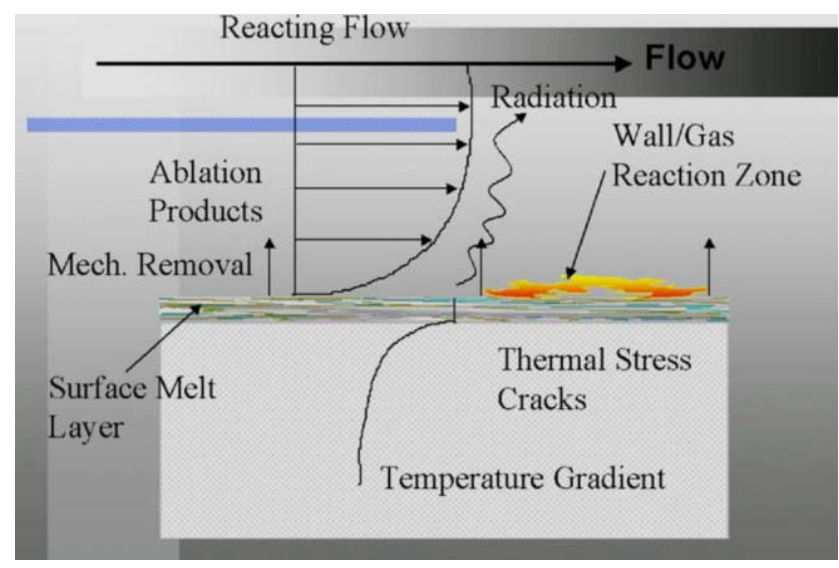

Fig1. The thermal-chemical-mechanical erosion mechanisms for a transient gun firing. (Lawton, $B$. 2001)

The chemically affected zone or layer (CAZ/CAL) of the barrel material also called as the white-layer is of the order of one to tens of microns deep and often penetrated by cracks. CAZ has been reported to influence the Chemical driven erosion. Heating of the CAZ drives phase changes, melting, and crack formation, speed of diffusion and reaction rates, affecting not only the virgin barrel material but also the reaction product species. The CAZ usually consists of distinct outer and inner white layers. The outer layer 
contains products from the surface reactions, including iron carbides, oxides, nitrides and retained steel in both austenitic and martensitic phases. The inner layer primarily contains carbon and nitrogen precipitates distributed through retained austenite. Most commonly cited chemical processes are carburization, oxidation, hydrogen erosion embrittlement and cracking.

\subsubsection{Carburization}

The propellants containing carbon produces $\mathrm{CO}$ and $\mathrm{CO}_{2}$ on combustion, and may also produce monatomic carbon at the hot gas-bore interface via reactions such as

$2 \mathrm{CO}=\mathrm{C}+\mathrm{CO}_{2}$, and

$\mathrm{CO}=\mathrm{C}+\mathrm{O}$

The carbon thus produced diffuses into the barrel forming a solid solution with the gun steel. Even though carburization increases the surface hardness of steel, excess carbon may precipitate out of solution as the barrel cools. The carbon precipitates as iron carbide compounds through reactions such as

$3 \mathrm{Fe}+2 \mathrm{CO}=\mathrm{Fe}_{3} \mathrm{C}+\mathrm{CO}_{2}$.

The brittleness of the bore surface increases as the content of cementite increases and it also lowers the melting point (by 50-400 K), increasing the chances of material removal by thermal and mechanical means.

\subsubsection{Oxidation}

Oxygen, byproduct of combustion diffuses into the metal surface and tends to oxidize it, similar to the formation of cementite. The reaction is as shown below:

$\mathrm{Fe}+\mathrm{CO}_{2}=\mathrm{FeO}+\mathrm{CO}$

The iron oxide forms a brittlescale layer, highly susceptible to cracking and erosion. Oxidation in un coated barrels may lower the surface melting point by 100-200 K, thereby encouraging thermal erosion also.

\subsubsection{Hydrogen erosion, embrittlement and cracking}

Majority of the researchers believe that most of the chemical erosion takes place due to oxidation and carburization. There are significant numbers of researchers who believe that hydrogen is one of the dominant erosive species. Lawton's correlation shows, diatomic hydrogen gas the most erosive species based on the firing data. Kimura explained that the erosion effect is primarily one of heat transfer: the thermal conductivity of hydrogen is six times higher than nitrogen (Kimura et al). Krishnan and coworkers concluded that atomic hydrogen diffuses into the barrel, reacts with carbon, and decarburizes the steel. Carburization increases the hardness of steel but also increases the brittleness. Most researchers hold that carburization promotes erosion due to increased brittleness and cracking, allowing mechanical and thermal removal. Decarburization promotes erosion by excessive softening of the bore surface. Sopok performed numerical model for test cases including a generic Howitzer and generic tank gun which indicates that addition of lubricants increases the hydrogen availability in the barrel environment. Localized adiabatic combustion causes dissociation of diatomic hydrogen to monoatomic hydrogen which acts as a contributor. Development of stoichiometric propellantlubricant combinations are suggested as a way of decreasing the hydrogen richness and relieving the problem.

\subsection{Thermal Erosion}

High flame temperature propellants may produce combustion gases at temperatures as high as $3700 \mathrm{~K}$. Heat transfer through the gas boundary layer is the primary mechanism. Besides convection, heating due to the sliding friction of the round and radiative transfer may also occur. Since the heat transfer from the propellant combustion to the barrel surface takes place in only a time span of 20-30 milliseconds, a lot of heat is accumulated over the barrel surface, usually at a depth of $1 \mathrm{~mm}$ only. The temperature of the gases decreases as the expansion proceeds, thus thermal erosion is critical only at the initial part where the rifiling commences.

Lawton's original correlation shows that erosive wear at the commencement of rifiling is approximated by an exponential function of maximum bore temperature $\mathrm{T}_{\max }$. Lawton's improved correlation goes further by taking exposure time into account. In both cases, though, the temperature dependence of erosion is strong. In theabsence of changes in propellant gas composition, for gun steel of typical hardness a $10 \%$ increase in $\mathrm{T}_{\max }$ results in an increase in erosion of 250\%. High flame temperature propellant formulations may lead to high bore temperatures, it is often reported in the literature that hot propellants are highly erosive. Thus itis commonly assumed that erosion will be reduced by developing low flame temperature propellants.

There are several physical processes identified in the literature as responsible for thermal erosion. In the so-called melt-wipe process, the bore surface material is melted and the liquid is wiped away through the mechanical action of solid particles entrained in the propellant gas flow or by the flow itself.

\subsection{Mechanical Erosion}

The mechanical properties of the CAZ (white layer) being degraded makes it susceptible to removal by mechanical means. The barrel with coating, are 
susceptible to subsurface production of loosely packed oxides which may cause an expansion effect. The expansion raises the coating which the projectile will engage and remove during firing. Even if the surface is not raised the shear force introduced by sliding friction alone is enough to remove material from a cracked, degraded or thermally-softened surface. Mechanical erosion also includes abrasion, sweeping and washing actions of the propellant gas flow including any solid particles entrained within it, by virtue of momentum. Leakage of high-pressure propellant gas past the projectile during firing can create jetting, thereby increasing erosive flow effects. This is called erosion by blow by flow between the projectile and the barrel surface. The orientation of the crack is also considered as a key parameter in mechanical erosion.

\section{Erosion Mitigation}

The understanding all the above mentioned mechanisms has led to development of various means to reduce erosion in gun barrel. Most primarily used erosion mitigation tools are: development of less erosive propellants; the use of coatings, treated barrel materials and liners; and erosion-reducing additives and lubricants.

\section{Conclusion}

To reduce the rate of erosion following conclusions can be made from the review:

1) Use of low flame tempe

2) rature propellants.
3) Avoiding use of lubricants to reduce the probability of hydrogen embrittlement.

4) Use of viable surface coatings like Chromium, Tantalum, and non-metallic coatings like foam, special power coatings etc.

5) Use of high nitrogen content solid propellants.

\section{References}

Lawton, B. (2001) Thermo-Chemical Erosion in Gun Barrels, Wear 251(10), 827-838

Lawton, B. (1984), Thermal and Chemical Effects of Gun Barrel Wear, in 8th InternationalSymposium on Ballistics, Orlando, United States.

Kimura, J. (1996) Hydrogen Gas Erosion of High-Energy LOVA Propellants, in $16^{\text {th }}$ International Symposium on Ballistics, San Francisco, United States

S. Sopok, C. Richard, S. Dunn(2005), Thermal-ChemicalMechanical Gun Bore Erosion of an Advanced Artillery System part one: Theories and Mechanisms, Wear 659670 ,

Clive Woodley, Ray Critchley, Dave Walligton, (2004), QuintiQ Studies on wear and erosion in gun Barrels.

D. C. A. Izod and R. G. Baker, Gun Wear: an Account of recent UK research and New Wear Mechanisms

John H. Underwood,( 2005) Thermo- Mechanically Controlled Erosion in Army Cannons: A review, Gun Tubes Conference, , Keble College Oxford.

P. Franco, H. Peter, (7-11 May 2001) Gun Barrel erosion: Study of Thermally Insulating Layers, $19^{\text {th }}$ international Symposium of Ballistics, Interlaken, Switzerland.

Lawton, B. (2003) Influence of Additives on the Temperature, Heat Transfer,Wear,Fatigue Life, and Self Ignition Characteristics of a $155 \mathrm{~mm}$ Gun, Journal of PressureVessel Technology 125(3), 315-320. 